\title{
Maximalism as a Cosmopolitan strategy in the art of Ruth Novaczek and Doug Fishbone
}

Article

Accepted Version

Garfield, R. S. (2016) Maximalism as a Cosmopolitan strategy in the art of Ruth Novaczek and Doug Fishbone. European Review of History, 23 (5-6). pp. 961-977. ISSN 1350-7486 doi: https://doi.org/10.1080/13507486.2016.1203880 Available at https://centaur.reading.ac.uk/66101/

It is advisable to refer to the publisher's version if you intend to cite from the work. See Guidance on citing.

To link to this article DOI: http://dx.doi.org/10.1080/13507486.2016.1203880

Publisher: Taylor and Francis

All outputs in CentAUR are protected by Intellectual Property Rights law, including copyright law. Copyright and IPR is retained by the creators or other copyright holders. Terms and conditions for use of this material are defined in the End User Agreement.

www.reading.ac.uk/centaur

\section{CentAUR}


Central Archive at the University of Reading

Reading's research outputs online 
Maximalism as a Cosmopolitan strategy in the art of Ruth Novaczek and Doug

\section{Fishbone}

Rachel S Garfield, Dept of Art, University of Reading

r.s.garfield@reading.ac.uk

Department of Art

University of Reading

1 Earley Gate

Whiteknights

Reading RG6 6AT 


\author{
Abstract \\ Ruth Novaczek and Doug Fishbone: Cosmpolitanism, Jewishness and Art
}

This paper looks at the work of the experimental film-maker Ruth Novaczek and the artist Doug Fishbone to think through the relationship between the cosmopolitan imagination, Jewishness and the visual arts. I suggest through my analysis of their art work that both artists proffer a cosmopolitan subject that arises out of their Jewish subjectivity. I will do this in different ways, discussing the artworks both in their various forms as well as the subject matter within the films.

I will think through two recent publications on the cosmopolitan and art by Marsha Merskimmon and Nikos Papastergiadis to discuss what is at stake in the cosmopolitan in relation to the two artist case studies. Central to my argument is a maximalist tendency that goes against the usual current paradigmatic trend of the "long look" that was first articulated by the influential André Bazin as more real than the dialectical editing techniques argued (and performed) by Sergei Eisenstein. But neither am I arguing for a return to Eisenstein. Maximalism, as offered by the work of these artists signifies an excessive overloading that allows the viewer to insert themselves into the narrative of the work through the editing, the collage, and in the density of the range of the material.

Finally, I will be bringing the formal discussion into dialogue with the explicit meaning developed by the art-work. Each of these artists proffer an unstable subject that is profoundly formed out of their Jewish and Diasporic subjectivity. This arises not just out of the formal structural scaffolding of the work but in terms of the subject matter within the work. They both explicitly use Jewish cultural references as a normative navigational tools in the work and as a way of forming their cultural worlds. These references range from dialogues of Jewish characters in cinema, to Jewish jokes and use of Yiddish or Hebrew. Importantly Jewish religion or ritual is absent. For both of these artists the Holocaust is a backdrop but not as way to valorize a victim status but as a way to reach out to a wider humanity and to understand its legacies. This is done through multi-positionality and the questioning of what a 'home' might be outside of an attachment to a nation state or a singular geographic location and embracing that estrangement.

In sum, I will argue that the work offers a reiterative provisionality as a refusal to judge or to know the world; instead there is an attempt to incorporate its complexities and range into the vision of the work, challenging the viewer to identify what is at stake in the work and in the subject. 


\section{Insert 5 keywords}

Maximalism, Lens based Art, Experimental Film, Jewish Identity,

\section{Cosmopolitanism,}

I will be looking at the artworks by Ruth Novaczek and Doug Fishbone in order to pose the question of how can art reconstitute the subject and what possibilities this offers for re-imagining the cosmopolitan. I will discuss theories of the cosmopolitan as they form through the art-work, first setting out the context briefly in art theory through which I analyse these works. Ruth Novaczek and Doug Fishbone are brought into focus here due to their use of collage that offers an alternative paradigm to the prevalent trend in much lens-based art of neo-minimalist tropes such as Sam Taylor Wood or Bill Viola to name just two high profile examples.. This alternative is what I will identify as maximalist, and one that I will delineate through the case studies themselves. The aim is not to bring these artists into direct contrast but for each to exist as parallel examples of the aesthetic that I am proposing. Most mainstream narrative film uses the shot, reverse shot sequence to establish a visual trajectory that informs the viewer of the relationships and the direction that the narrative is taking. In artists' film, this has given way to the use of a series of long shots as the central paradigm that slows down the classic mainstream trajectory. This long shot trope, I suggest establishes a focus of linear singularity. By contrast both artists I focus on here, in their own ways use collage as a means to invoke a world-view that encompasses a multivalent vision in a single sweep of thinking; that is within a single passage of video or art work. The interlinking of images in a way that is fragmented, overlapping and non linear is particular and it is this particular formal device that I will be analyzing as a feature of the cosmopolitan in the case studies.

In order to do this I must first introduce the main body of recent writing that approaches the idea of the cosmopolitan in art in the UK, which is the contribution by 
the art historians, Marsha Merskimmon and theorist Nikos Papastergiadis. They both posit the cosmopolitan as important ground that artists have identified and taken on. I am an artist and my own field of study is art. It is this that gives rise to the aims and interests here. In order to look at how the cosmopolitan subject can offer insights through the artwork I must first look briefly and therefore broadly at the way explorations into subjectivity have been characterized in the prevalent debates in recent decades in art specifically. These of course are informed by broader discussion on the cosmopolitan but the scope of this paper requires that I focus on Merskimmon and Papastergiadis.

Key art critics, particularly those clustered around the influential October journal, ${ }^{1}$ since the 1990 s have declared that exploring identity in art is narcissistic and that personal narrative is self-serving. ${ }^{2}$ These claims have effectively marginalized work that uses the "self" in the arts that is exemplified by Ruth Novaczek's oeuvre which has been given relatively little critical attention and not had the visibility that her peers whose work does not deal with identity have had. In many cases I would concur with their argument that a focus on personal narrative or the self as a conduit for affirming identity is in many ways problematic. ${ }^{3}$ The issue at stake is to ask what purpose art serves. The criticism that marginalized this kind of work was exactly that it is conservative as opposed to avant-garde - as the art historian Benjamin Buchloh stated in the aforementioned discussion within the Art journal, October "I'm not sure that the project is to critique identity ${ }^{4}$ I'm not sure that's the project of some of these artists. They would much rather be associated with a project of affirming and constructing identity. The articulation of the work is an act of empowerment, of conscription, of consolidating identity." It was this discussion that proffered a turning away from focusing on one's own cultural identity in mainstream art circles within a climate in the art world that art was to critique society rather than conserve tradition. I would agree that the work of personal narrative that Buchloh refers to here does not aim to rethink subjectivity in a complex world, but serves to assert the subject's special qualities because of the history of marginalization and victimhood as an ethnic insiderist manoeuvre. However, not all work exploring identity has this feature. The 
work I am championing does not. Instead it uses a heterogeneous approach to narrative and identity through a maximalist aesthetic. Maximalism offers a complex subjectivity that I will explain through the case studies. The complexity that the work constitutes could be seen as the difference between an impulse to "find oneself" compared with the impulse to question why identity might matter and how this can open up possibilities for the future. Novaczek's Rootless Cosmopolitans is an example of this as she posits Jewish identity through the question What is a Jew? at the opening the film, not as statement of fact. Furthermore, the film refuses to give a singular answer instead delivering a wide range of possible narratives that all revolve around the question posed at the beginning of the film.

To situate cosmopolitanism and Jewish identity together may be problematic even after Kwame Anthony Appiah's important contribution to the idea of rooted cosmopolitanism. Jewish cosmopolitanism implies the foregrounding of the culture as the identity of origin, which in turn may seem borne out of a need to hold on to the nostalgic desire to belong to a cohesive community. I have long argued for a relationship to culture as being citational and against the tendency towards nostalgia or imagined cohesion in relation to identity politics that seem particularly prevalent in relation to Jewish artists. Certainly in curatorial choices if not the artists' own, there is a domination of the impulse to either celebrate Jewishness that can be seen through examples of many Jewish museums ${ }^{6}$ or to mine one's history for roots or atrocities Judy Chicago and Susan Hiller being prominent example ${ }^{7}$. I would go so far as to say that the desire for wholeness and restitution from a victim past is often the driver of Jewish work rather than the seemingly existential isolation of the cosmopolitan ideal of the "citizen of the world." Jewish choose not to make Jewish identity figure in their working practice in any way. Even when they do, disavow intentionality, which in itself declares a hegemonic trope of disinterested internationalist uniformity that is actually a Euro-American aesthetic. ${ }^{9}$ There are of course notable exceptions such as the aforementioned Susan Hiller or Judy Chicago, but these are exceptions who prove the rule, for neither made "Jewish work" until they were established in their reputation and for both these artists, the 
"Jewish work" is the most conservative in concept of their respective oeuvres. So the apparently existing dilemma is whether to make celebratory Jewish work or work that buries any visibility of Jewishness at all. ${ }^{10}$ I consider this a reductive binary and a lost opportunity to rethink a more radical Jewish subjectivity through the visual imagination. Doug Fishbone and Ruth Novaczek's work offer such a radical Jewish subjectivity through a multivalent collage that gives form to the complexities of negotiating a Jewish lived reality.

My focus and emphasis here is not to argue for a redefinition of cosmopolitanism but to find a language to talk about the subject in art. I also do not aim to privilege the 'theory' in order to use the art as examples of the theoretical positions but instead to analyse the art for what it can offer to inspire and expand our understanding of subjectivity. I will demonstrate that Doug Fishbone and Ruth Novaczek find a way to make work that is infused with questions of cultural identity (in this case Jewish) while suggesting a position that has no truck with ethnic insiderist tendencies of reinscribing difference as a special case. I will argue that their work creates an equalising force of chains of equivalence that the cosmopolitan demands and that I will argue for in these artworks. A cosmopolitan outlook not so much grounded in particularity but having a citational relational tension with it.

With this in mind, I would situate Natan Sznaider as an important voice in my argument as someone who discusses the relationship between universalism and particularism as being "a co-existing pair." In "Memories of Europe: Cosmopolitanism and its Others," Daniel Levy and Natan Sznaider argue, that we should be talking about cosmopolitization as a process rather than cosmopolitanism as a noun. They suggest that we should be articulating an ongoing and incomplete process rather than using the ahistoricisity and fixity of the noun.Both artists I write about suggest Jewishness as an incomplete process. Furthermore both artists celebrate the Jewishness as an ongoing process through the maximalist methodology of overloading imagery that doesn't cohere. Fishbone for example montages multiple still images gleaned from the internet back to back. Sometimes the images make sense 
and sometimes not, the viewing process being one of moving between the images in a way that doesn't offer a seamless denouement. The lack of ending or linear narrative drive is analogous to what Levy and Sznaider is proposing. It is cosmopolitisation in action through the video.

Cosmopolitisation would acknowledge, they argue, that the central plank of cosmopolitanism, that is European Enlightenment, continues to exclude and particularise (the former resulting from the latter). They argue for cosmopolitisation as a way of ousting the parochialism of Europe. ${ }^{11}$ In this spirit I would consider Jewish cosmopolitanism not so much as "rooted" but more of the relationship of an ongoing dialectic. Both artists' work offer a response in formal terms to the criticism of Levy and Sznaider and possibly to the idea of a local (i.e., European) cosmopolitanism. For Novaczek, the device of taking sound and image apart so that the viewer cannot tell how the cultural references relate to each is a process that the viewer takes part in, by trying to make sense of the disjuncture and in the case of Fishbone, the same device used differently, as well as the incoherent sequences of images the disjunction between the narrative and image the viewer partakes in the process through trying to make sense of the way the visuals lend meaning to the narration.

In sum, I will argue that suturing these two notions - of Jewish and Cosmopolitan together may offer, through a dialectical relationship, a way out of the impasse many find themselves in, of a desire to belong to a single or singular community, however one perceives that to be at the same time as positioning oneself through the ethical position of being part of a world community.

\section{In Contemporary Art and The Cosmopolitan Imagination, Marsha Merskimmon} makes her case for art and a cosmopolitan vision as a reinvigorating force in art, "It is my contention that a cosmopolitan imagination is key to engendering a global sense of ethical and political responsibility at the level of the subject." 12 Throughout her book she identifies the cosmopolitan as exemplified through a nomadic art practice 
that situates oneself at home or enables one to make a home in any location, moving home from "a fixed site to negotiable situation,"13 and does this in various ways using a range of examples throughout the book. Merksimmon reclaims and links the terms nomadism and cosmopolitanism, terms that have both been linked historically as a slur towards Jews. Her linkage is thus not surprising. The sedentary life in the Enlightenment was identified with the development of cultural and artistic sophistication and Jews were considered as nomads and therefore lacking in substance. Thus the term has gone from a nineteenth-century insult borne out of the Enlightenment ideology of progress, where the nomad is seen to be less developed than the sedentary communities of Europe, to a contemporary metaphorical figure that represents our epoch of global travel and internationalism in the global North at least. Like the nomad, the cosmopolitan is also a term that has undergone a process of recuperation: from the nineteenth-century attack on the Jew (and its Stalinist resurrection), the perceived unbelonging of Jews and 'rootless cosmopolitanism,' to the reconfiguration of the 'nomad' by important political and cultural theorists Chantal Mouffe, Rosie Braidotti and Iain Chambers. For Merskimmon the artist as nomad, making a home wherever she shows, is the key plank of her book.

What is at stake for me in this paper and why I champion the artists Ruth Novaczek and Doug Fishbone, in the ways that I am describing throughout this paper, particularly later through the second half where I describe the work in detail, is that their work offers a completely different example of what cosmopolitan art could be that is in opposition to Merskimmon's popular argument for the nomadic artist. Both artists work with the idea of the global within the imagery and the textual narratives of their work, not in following a nomadic lifestyle themselves. The work thus operates on a metaphorical and analogous level rather than the literal methodology that much of the work within Merskimmon's book follows. Within the context of the art world or academia the nomadic subject is a figure of privilege that excises the politics of lived relations, which endows it with both specificity and urgency. ${ }^{14}$ In art, it does this in a way that through symbolic or poetic gestures elevates metaphor and glosses over an often-brutal reality. The emergence and ongoing popularity of the 
artist Francis Alÿs for example is a testament to the prevalence and popularity of the nomadic as beacon in art for a cosmopolitan ideal. ${ }^{15}$

The other writer within the recent interest in the cosmopolitan and art is Nicos Papastergiadis, who in, Cosmopolitanism and Culture, offers a slightly different emphasis and engagement with the trope of the cosmopolitan and what is at stake and much closer to the outlook of Novaczek and Fishbone, who are locally grounded and globally oriented.

Although globalization is increasingly identified as a threat, it is equally clear that the desire to stage an open conversation between the local and the global has emerged as a core aim among artists. This broad expression of aesthetic cosmopolitanism is evident in a range of locally grounded and globally oriented artistic tendencies. ${ }^{16}$

What is at stake for me in the formulation of the, the artist as globetrotter engaged in the business of biennale exhibiting is a good example of how class is conveniently put aside in assumptions about the conditions of cultural identity. In any event, the artist who gets to travel the world belongs to a privileged class of artist who doesn't make herself at home by investment and engagement in the places of exhibition but instead stays a few days here or there or a few months/weeks here or there in a residency supported by a network of grants and bursaries supported mostly by national interests and sometimes by wealthy philanthropy. In other words, I would argue that this is a form of cultural colonization and soft power closely tied to the neoliberal ideals: (much like the criticism of Cosmopolitanism itself that has been argued as a privileged paradigm for the globetrotting Westerner). These artists are also a tiny minority: most artists work under precarious local conditions to support themselves and their practice. The trope of the cosmopolitan artist through the representation of a $\underline{\text { sense of the global (making work about the wars that happen elsewhere or the poverty }}$ and so forth) is not the same as the subject position that the artist themselves may 
inhabit. There is a slippage here between the abstract and concrete conditions of the artist in the global world. (The underlined bit just able - is the kind of claim that $i$ understand does not have the specificity required of the discipline (History) but is self evident enough for art theorists not to need further proof. It is also important for me for the underpinning of why the nomad is such a flawed concept in the art theory idea of the cosmopolitan - if you have to take it out for that reason then do but $i$ would prefer it in. It is not relevant to explain how this specifically fits with the case studies art but is core to the spine of my arguments)

It is in these definitions that my own outlook emerges through the choices of art practice to call up within this purview. My own examples exemplify a rebuttal of the pervasive cinematic trope that requires big teams, big budgets (in artistic terms) and the need to travel to shoot what is "elsewhere." They offer an alternative to expensive installations that require fabricators and a team of technicians. Instead Ruth Novaczek and Doug Fishbone work with lo-fi, imagery that is accessible without a budget on equipment that is generally affordable. ${ }^{17}$

Finally I would suggest that in usual discussions of so-called issue based work, and certainly in my own experience of discussing my own video work in public, content tends to override form in analysis generally. I will argue here that one constitutes the other in a relationship that is hard to disentangle but important to consider equally.

I will also argue that the importance of work that questions form as well as content allows for agency of the viewer through the imagination and slippage of repetition and parallel editing. Both the artists that I consider eschew visual narrative structure in favour of a re-invented parallel editing. According to Mary Ann Doane, there are three types of editing in early cinema, each of which creates its own drama. ${ }^{18}$ The first is shot followed by reverse shot, as described earlier, using repetition to create narrative coherence. The second is the chase, popularised through comedy and thrillers, which serves to re-inscribe linear time. The third is parallel editing which 
creates a jump in space and time, implying that two events occur simultaneously. Parallel editing, unlike the classic shot, reverse shot, is editing where there is no linear accumulation of meaning but instead a disjunctive range of shots that fold in a leap of time or space creating meaning in a different way. While the chase edit 'aggregates regularity' and creates normality, parallel editing creates suspense through desire and fear, which, according to Janet Harbord, 'displaces the temporal logic of film, creating a simultaneity that requires the spectator to insert herself into the relationship between images, to forge connections. ${ }^{19}$ Parallel editing is essentially a kind of montage that can offer an effect of collage as it venerates contingency like no other cinematic form. It is an edit that has a gap in meaning through its contingent incoherence. In this way it privileges heterogeneity rather than singularity as an equalizing force that works as a powerful metaphor for the cosmopolitan in ways that I will explore through the case studies.

Ruth Novaczek (b. 1956) is a film-maker who emerged in the 1980s out of the famous film Dept of the then St Martins in central London. Doug Fishbone (b. 1969) is a younger artist who did his MFA at Goldsmiths London, graduating in 2004.

Novaczek has generally screened at film festivals and Fishbone exhibited in galleries, however there is some crossover.

Ruth Novaczek uses video, working with montage through parallel editing and Doug Fishbone uses internet derived stills but choreographing them through repetition and collage. The disjunction that collage and montage affords allows for the interplay between the rational observation, analysis and affect or excess where repetition opens up a possibility for a re-interpretation by the viewer. Both artists play with this trope in slightly different ways but for both artists the effects of heterogeneous imagery is fundamental to their building of subjectivity in the work. It is in the equalizing sweep of this heterogeneity that the cosmopolitanisation is evoked. Heterogeneity as it is offered through the work of both artists evokes a sense of incompleteness and a dialectic as proposed by Levy and Sznaider, although importantly both artists were 
developing this work before the suggestions of these sociologies and as such can make claims to constituting these ideas through their art.

Collage has been posited as a Diasporic concern by Kobena Mercer drawing on the African-American writer Ralph Ellison, registering inequality through 'sharp breaks, leaps in consciousness, distortions, paradoxes, reversals, telescoping of time, and surreal blending of styles, values, hopes and dreams. ${ }^{20}$ Ellison notably developed this technique from Romare Bearden's projected photomontages. Mercer suggests that the disjunctions in the imagery across the collages and photomontages cut (as they are themselves cut) through the meanings of Blackness (and the power of those meanings) as it traverses the twentieth century through different assignations from 'Negro' to 'coloured' to 'Black.' The cut then stands as witness to, 'the dialectical flux of historical becoming. ${ }^{21}$ In this way, montage and collage could be seen to be of particular interest to artists working in the Diaspora. While the focus on the subject matter of art that is dealing with war and global power politics is associated with what might be called a cosmopolitan turn, my own claims and argument is more to do with the ways in which the subject emerges and re-emerges in the world through art as a cosmopolitisng effect.

Novaczek's oeuvre draws from the New American Cinema and the WWII American film making tradition, which is humanist in sentiment and believed in the integrity of the lo-fi aesthetic and the vision of the artist to express modern life from the streets. Her work is cosmopolitan and proudly Diasporic, "I am from the Diaspora," she actually states in one of her films in response to a cab driver asking her where she is from. Many of the filmic devices that Novaczek employs lend themselves to this reading: fragmentation, collage, composition and multiple voices. Each of these devices gives the viewing subject the means to take on what the cosmopolitan offers. As an inversion of Merskimmon's thesis, Novaczek doesn't take her rootedness to the world but brings the world to her (and us): a more outward looking approach to the cosmopolitan. Although I'm focusing on "Rootless Cosmopolitans" any one of her films could be analysed from a cosmopolitan point of view. 
The film is made with a lo-fi aesthetic. Amongst film-makers there is often a pragmatic reason for the aesthetic decision. This lo-fi aesthetic is also framed as an authentically driven camerawork that foregrounds experience as the focus of the filmmaker as she is filming the world. However, while in keeping in some ways with this ethos of the New American Cinema through her approach to camerawork and their views on the authentic experience, Novaczek's work also departs from them in her critiques of the authentic subject in films such as Philosopher Queen (1994), funded by the Arts Council, where she parades a range of different 'selves' in front of the camera in a panoply of undecideability. There is no stability in the subject in Philosopher Queen which is more in keeping and possibly prefigures in its own way the work of younger artists such as Nikki S Lee or Oreet Ashery or indeed my own. Novaczek also departs from the Post War thrust in her self conscious and selfreflexive borrowing of their "authentic" language of shooting place. Her focus on Americana and its impact on post WWII British Jewish sensibility through cinema and the novel is particularly pertinent to a contemporary awareness of history and subjectivity.

All that sits alongside the way her camerawork and filmic structure creates a subject who is a citizen of world through multiple images of places that are not site specific and while evocative, cannot be identified but repeat in a way that overloads the senses. This is not a construction of a singular subject but a shifting subject, provisionally constituted through many contingent possibilities that gives the film a global context but one that is not specified nor specific and therefore cosmopolitan in its lack of identifiable originating location. The works are always moving, with camerawork that feels like it is not able to finish or finesse anything because her subjects are never in one place long enough to do so, 'always running towards something' as Novaczek states in Rootless Cosmopolitans.

"What is a Jew?" is the question that begins the film of Rootless Cosmopolitans. This is not a narrative film. As a response to the opening question the 
film offers an episodic set of vignettes: of women in the city, who suggest some kind of female equivalent of the urbane Woody Allen and their interior world. The narrator introduces two women as friends. The film very quickly moves to a conversation between these women that draws an equivalence between blacks and Jews and questions of who looks Jewish and who looks black. The contradictions are cited by the protagonists - of identification across the two groups - the identification of Jews with whiteness and the anti-semitism of Farakhan. The ease of the discussion in the film between black and Jewish women, in itself sets up a counter narrative to the cited identification. The narrator is a minor player in the sound as multiple voices begin to tell their stories. "Lily's mother Marcelle. They weren't exactly a chicken soup kind of family" She is sitting in a car smoking, while the voice over tells this story of her family..." She comes from a travelling family. Jews they live here then the borders change" all the while the subject, is silently smoking and talking. "I came here in '39. I just earned a living..." the subject speaks but the voice is disconnected from the image of her smoking and talking and walking with her daughter in the Street. Lily, the subject then moves back to the existential questions, talking about accepting her Jewishness and what it means. Thus moving from the existential to the personal and back again - in this way the everyday and history are intertwined. The multiple voices, disconnected from the image make equivalences between people and peoples - in a later passage the subject tells the story of her grandmother getting elocution lessons and the image shifts between two elderly women: a European dressed woman and a woman in a white hijab - the narrative could apply to either of them and thus confounds assumptions of community, belonging and identity at the very moment that it identifies it.

Novaczek's "always running towards something" can offer another way of thinking about the cosmopolitan, and here I will return to Papastergiadis who is clear not to focus on art that dwells on cross- cultural issues nor even on the processes of structural global interfacing, both of which I would add instrumentalises the methodologies and forms of art making but art that " is concerned more with the proposition that the process of world making is a radical act of the cosmopolitan 
imaginary." 22 He uses in part the idea of the stoa, which is just such a place that Novaczek visualizes in her work, as an integral part of the envisioning of ancient Greek cosmopolitanism that was less formal or permanent than the oikos (home) and more intimate than the agora (public space) and less formal than the bouleuterion (parliament). "I imagine the stoa as a spatial metaphor for the emergence of critical consciousneess within the transnational public sphere. It is a space for criticality without the formal requirements of political deliberation and sociality without the duty of domestication' ${ }^{23}$ In the passage that follows in Novaczek's film, the idea of 'world making' happens in a sphere that is both intimate as it is public. Importantly the camerawork and narrative incorporates the oscillation between those two states and it is this that conjures up for me exactly the moment of the stoa that Papastergiadis delineates as the metaphorical place of the cosmopolitan.

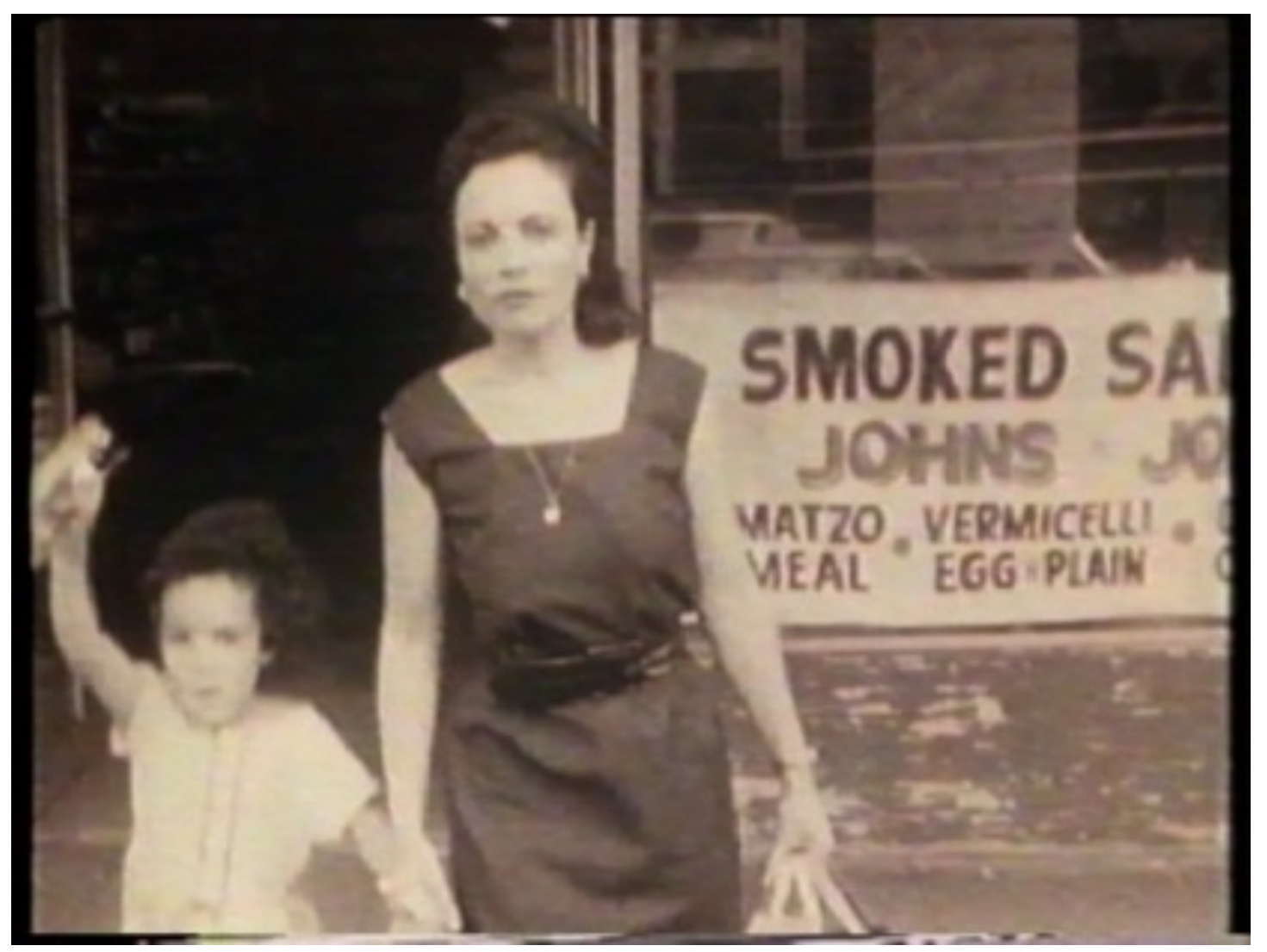

Ruth Novaczek, Rootless Cosmopolitans,

Rootless Cosmopolitans is shot in black and white, in fragmented moments of urban images. Most of the film uses voiceover to comment and explain. It also adds a surreal quality, undermining any sense of naturalism, implying a structuralist 
approach to the subject "She is here because of this context" kind of structuralism. The film brings past and present together, interweaving longing to belong but questioning to whom and to where. The form of the film is broken, fragmented, the image and the footage is purposefully degraded. The disjunction between sound and image in some passages makes sure that the viewer cannot be sure who is talking and who isn't. This device of undecideability impedes possible judgement of the viewer for the filmic subject, equalizing the subjects who speak. Furthermore this work has a temporal dislocation also. The temporal is evoked through the black and white film stock, the vintage clothes and in the allusion to post WWII street documentary of artists such as Helen Leavitt who were committed to exploring the everyday of the pavement. These indicate nostalgia for the modern moment while the voiceover and "cheesy" music signify a self-reflexive critique of that nostalgia.

In the second passage of the film the mood shifts from the conversations about Identity to a montage of disjointed images "in my dreams I'm a traveller but in my dreams I'm a Jew. In my life I'm running so much I can't see myself and I wonder where I'm running to. To orange trees or prison. Between Diaspora and Zion.” The images in this passage shift in a close succession of edits from a woman sleeping to a middle eastern building façade, to images overlaid and moving of fragments of a passport; a wrought iron gate; a shop window then sand dunes, a ship at sea, a train, urban scenes, a woman running, jackboots marching a shield of David drawn in chalk on the pavement, orange trees, a woman walking. This is a fast edit with klezmer music in the background cranking up the tension, to be brought back to earth with the voice over. Whereas the cosmopolitanism of the $19^{\text {th }}$ Century Zionists envisioned a Europeanisation of the intelligentsia in Zion, Novaczek's work forms an affinity with post colonial debates, with Blacks, Asians and Sephardi Jews, arguing against the over-determination of these categories through the visual in the pulling apart of image from voice and through the undecideability of these categories in her visual composition of subjectivity. There is no asymmetry between "East" or "West" in this vision. Nothing that tells the viewer what is East or West nor who is black or white 
and particularly not where the Jew fits into any of these categories that melt into each other in Novaczek's films. Everyone is mucking in together.

I would suggest that in terms of form, this is a quintessentially cosmopolitan passage in a film that explores the theme. It is a vision of multiples, multiple places, multiple voices and visions. The composition is tight so that the context is impossible to read. In other words, all context is made by the juxtaposition of images and the further juxtaposition of the music and the voiceover. Through the fast edits and the disaggregation of sound and image, Rootless Cosmopolitans questions these geographical and cultural hierarchies, here the Jew has no originating location. The continual close-ups ensure that the film is both particular but non-specific or looking at it through Szneider and Levy, the viewer experiences the processes of cosmopolitization in the build up of imagery and the dialectic between the universal and particular in the tight frame versus the multiple montage within each passage. They seem to take in sweeps worldly impressions coupled with specific faces that read as human. The lack of site specific context defies the idea of provenance. The pavement could be London. It could be New York - but it might not be. The film also posits multiple viewpoints, for example, in this montage, there is an image of a woman in a white raincoat running in the distance. She is being seen through railings. She is both a minute figure in the distance and in the centre of the shot. This recurs a couple of times but so does another shot that is looking down at the camerawoman's feet as she walks across the floor. These are simultaneously overlaid as with the other shots enumerated above - all happening at once in a destabilising gesture that asks the viewer to try and make sense of these floating signifiers that coalesce in an experiential world, only to 'run towards' more fleeting images of a different order in the following sequence. In the undecideability of the context and geographical location and in the sweep of the world through its maximalist and multivalent takes, this work offers a cosmopolitan imaginary.

Suddenly there is another shift in tempo. "When I have difficulty knowing where I'm running to I would go and see my cousin." The cousin is seen here sitting by some 
lupins in a garden, then with a group of people where she is telling a traditional fable then to a passage where the narrator and Lily Klein meet at a café by accident and discover a connection - a romantic relationship is implied. Thus the film travels from the global to the domestic from the existential to the specific and from communal, formal interactions to an intimate relationship. In this way no relationship, no interaction is privileged. Novaczek prefaces this work that is about Jews but destabilises the term even as she speaks it which I would argue is also an equalizing gesture that interconnects the citizens of the world. So this film offers critiques of nationalism; of the whiteness of Jews and their exclusivity; of rootedness as an aspiration and the cosmopolitan figure.

Doug Fishbone works with the idea of the collage and the disjunctions between image and voice to create the gaps and maximalist overload that Novaczek does through parallel editing. Whereas Novaczek's work emerges out of the tradition of experimental film, Doug Fishbone is situated within the art world and would consider his work gallery art. ${ }^{24} \mathrm{He}$ is a younger artist who has emerged in the early $21^{\text {st }}$ century, graduating from his MFA in 2004. He uses a range of deflationary devices to destabilise the power relations between the viewer and subject that cuts across the idea of hierarchies and place making.

"To grasp the dynamic of cultural cosmopolitanism we may need not only to consider the big shifts and wide networks of global change but also to ponder over how little commonality is now necessary before people find a connection with others." 25

Fishbone is interested in the possibilities of a subject that cannot be pinned down nor contained which he constitutes through a world constructed through mediated imagery and "shaggy dog" stories. His subjects have no authenticity nor specificity beyond the internet derived imagery, but yet create believable and recognisable personas that reach across geographical specificity because of the global reach of the internet and demonstrate how profoundly cosmopolitanising this reach is. Between 2003 and 2005 Fishbone made a group of works that combined a voice over and a 
vast plethora of still images corralled from the internet: the world Fishbone creates is one that is hermetically sealed within its confines and also, like Novaczek operates within the schema of the stoa in its somewhat cavalier approach to the subject. The subject here is constituted through the smoke and mirrors of mediated imagery that stretch modes of acceptability collapsing judgement: no one in this world can take for granted her place in the world nor attack anyone else's idea of place in the world. It is provisional, that is ever changing, depending on the word and image juxtaposition at any given time that itself never stops moving and this lack of stasis demonstrates the processes of cosmopolitanization.

In terms of visible Jewishness, Fishbone creates composites made of images of stereotypes of Jews, the magen david (shield of David) symbol, Hebrew words, photographs of the Shtetl (Jewish village) or Israeli soldiers and Jewish celebrities. He juxtaposes these with images of pornography, "trailer trash," animals smoking, the hammer and sickle and other symbols of ideology. This is not the elevated Jewish subject of the dominant paradigm in Jewish art, which follows an immersive lament for a past of loss and atrocity. It is somewhat abject. There is no pure subject in Fishbone's vision but the opposite of the elevation of ethnic insiderism: a deflationary Jewishness of the everyday dilemmas and problems.

These are short works, each between ten and twenty minutes and each has a similar format that involve an American East Coast voice philosophizing on life. The voice narrates over the still images in his films, as a riff on the stand-up comic, telling seemingly disconnected anecdotes, jokes and asides. He also performs live. The tales told conjure a neighborly breeze-shooting kind of effect replete with puns, platitudes and "common sense" laden misapprehension of the complexities of the world. There is a constant juxtaposition between the images that come and go and the story told by the narrator, clashing against the mundane drone of the voice that stretches modes of acceptability. The meanings created by the contrasting images and the narrative are problematic and challenging but too fast to reflect on to or even make sense of in a single screening. This is in direct contrast to the "long look" type of film that commits 
the viewer to contemplative reflection on the image slowly and beautifully unfolding. In the "long look" the point of slow is to help the viewer see the beautiful in the normal and the everyday: the tasteful of the long look versus the tasteless of Fishbone. The narrator, usually in cinema, is the voice of authority. In Fishbone's work the narrator becomes the trickster playing the imbecilic man of the people in order to undermine the power of that very figure. Using the seeming randomness of internet image searches (although these are carefully ordered), Fishbone creates a world with no apparent logic external to the tale he weaves and like Novaczek, this work is lo-fi and deflationary. However, unlike Novaczek, Fishbone's work is firmly antihumanist in its ethos situating the subject as formed through mediation and absent from the centre stage of his own construct. He does this culturally through the images of shtetl's, Chagall paintings, stereotypes of Jews, Klezmer music and snippets of Yiddish. That there is no certainty seems to be the main point at stake in the world of Fishbone's making. However, it is not individual images that create the overall meaning in the work but the maximalist overloading and the humour built up through the absurdities of the juxtapositions throughout the works. These absurdities delineates the contemporary dissolution of division between global and local, national and international, us and them as an everyday and ongoing practice. ${ }^{26}$ 


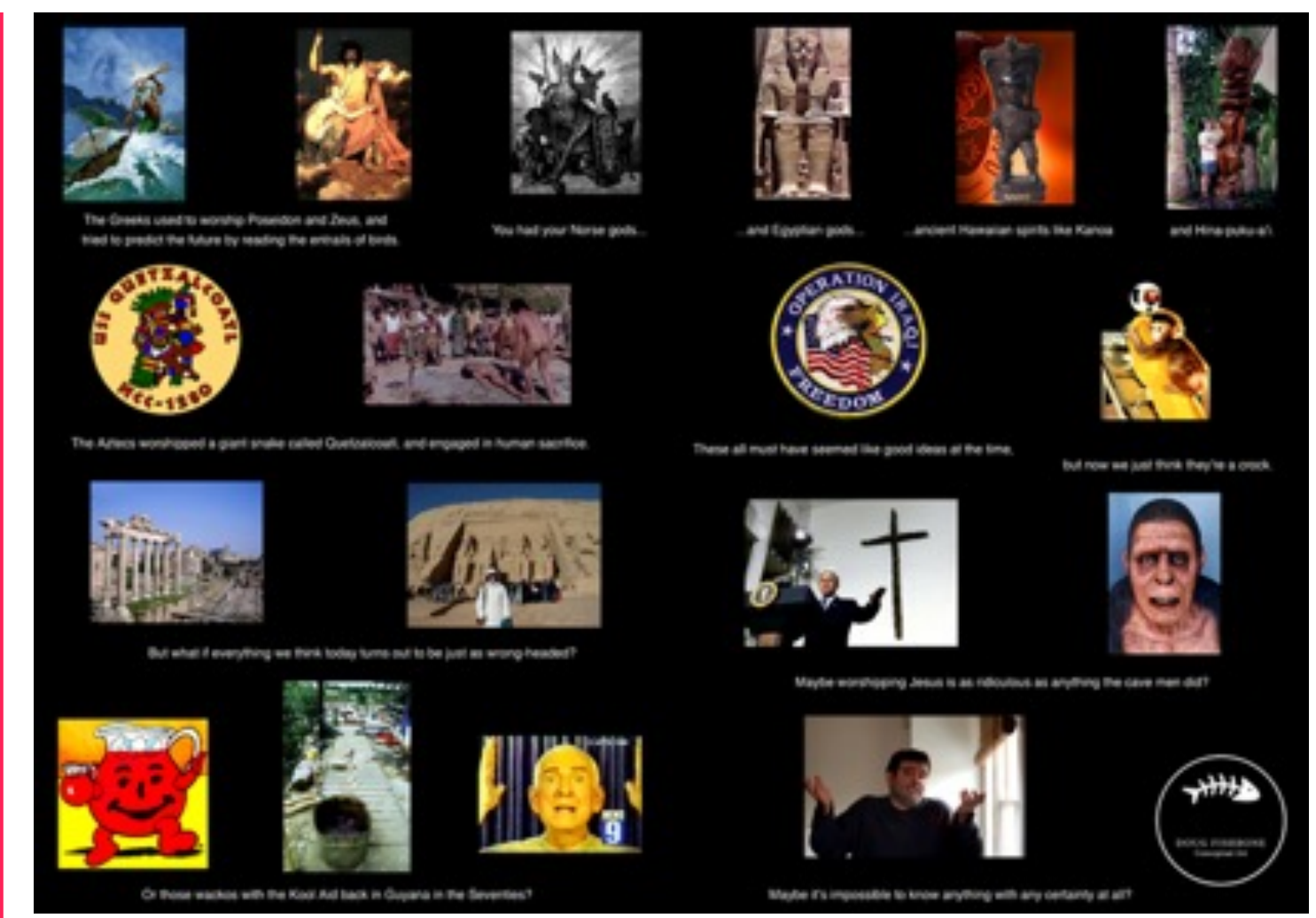

Doug Fishbone, Everyone Loves A Winner, Screenshots

One of the most interesting claims of the work is to question entitlement through a temporal inversion. It is striking that the works make a call to being out-of-time, "what if what we think now turns out to be as silly in the future as our past seems to us today?" the voice over asks, also asking if the wooly mammoth knew what it was called by humans or if the Inca's knew what period they were living in. He does this to make the point that we can never be safe in our assumptions of ourselves or of our understanding of the world. Fishbone thereby questions the supremacy of the contemporary, the embeddness of key assumptions of subjectivity and our place within it. I see this as a profoundly cosmopolitan device.

In the first film The Ugly American (2003), there is no redemption, just a relentless Lenny Bruce-inspired alienation and self-hatred and while the works are explicitly Jewish, the work naturalizes the Jewish voice and fuses it with an imbecilic, working class, homespun voice narrating lines such as “then there's that nursery rhyme, I'm sure you know it. 'Corn on the cob Paul Pott pie, dirty fat slob, were all gonna die'. You see life is a bit of a gamble and to be honest with you the dice have never seemed 
to go my way." Then he talks of his mother who was an alcoholic then his abuse by the priest then "but sometimes I wonder, what with all that recovered memory therapy" then a picture of Freud, stopping for a mere moment before continuing to talk about wanting to live in the country. The explicitly Jewish references interweaves with all other imagery in a way that deflates any special status of any kind. It is a collage - all that is available is to contemplate the whole composite piece in its entirety, losing the detail. For example in this film he asks the viewer "Can you see anything hidden?" showing an elephant with six legs, then the IMF insignia that shifts to contain an image of an anti-Semitic stereotype of a Jew. His tactics are shock tactics: he does not self-exoticise nor explain Jewishness in his work. Central to the piece is that he doesn't make the Jewish references key to the meaning of the piece either. In The Ugly American he takes the viewer into a world that he considers normal, with its mere smattering of Jewish references, yet a world that is not directed at a 'Jewish' audience but an assumed predominantly non-Jewish art world.

The fast moving imagery equalizes through visual overload. The work also equalizes class by mixing folding imbecilities into philosophical references and allusions. This overlap between different viewing publics is created through the wacky humor and through shock; Fishbone creates a crossover through the idea of eccentricity and imbecility as the new normal.

In Towards a Common Understanding the film begins with various images of fish, then a diver swimming beside the fish in his wetsuit, finally a bikini clad woman appears, then another giving way to an porn image of a woman, on her back, holding open the lips of her vagina. The narration over this display is, "My dad used to say, statistics are like bikinis. What they reveal is interesting but what they conceal is essential" the porn image is viewed just at the utterance of the word "essential," quickly giving way to a censored sign. The film goes on to talk about how we need to give order to the world all the while the film is ripping through images of war, The Bomb, Einstein. However the message is actually irrelevant, signaled by the contrast between the highly charged and deliberately provocative motifs and the message that 
is eventually delivered is a platitude: that we are all different. The message is thus revealed as irrelevant with the lack of message being the point. The platitude is also a deflationary tactic that situates the artist against what he is setting up- the narrator is not the seer that is the usual voice, but instead is an equalizer that intersects with the viewer forcing the viewers to think about the limits of their morals. 


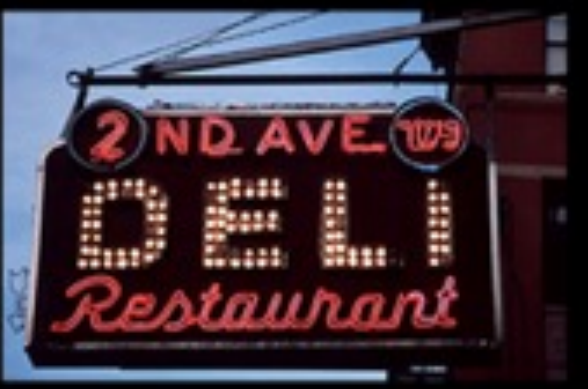

A gorilla walks into a deli in New York,
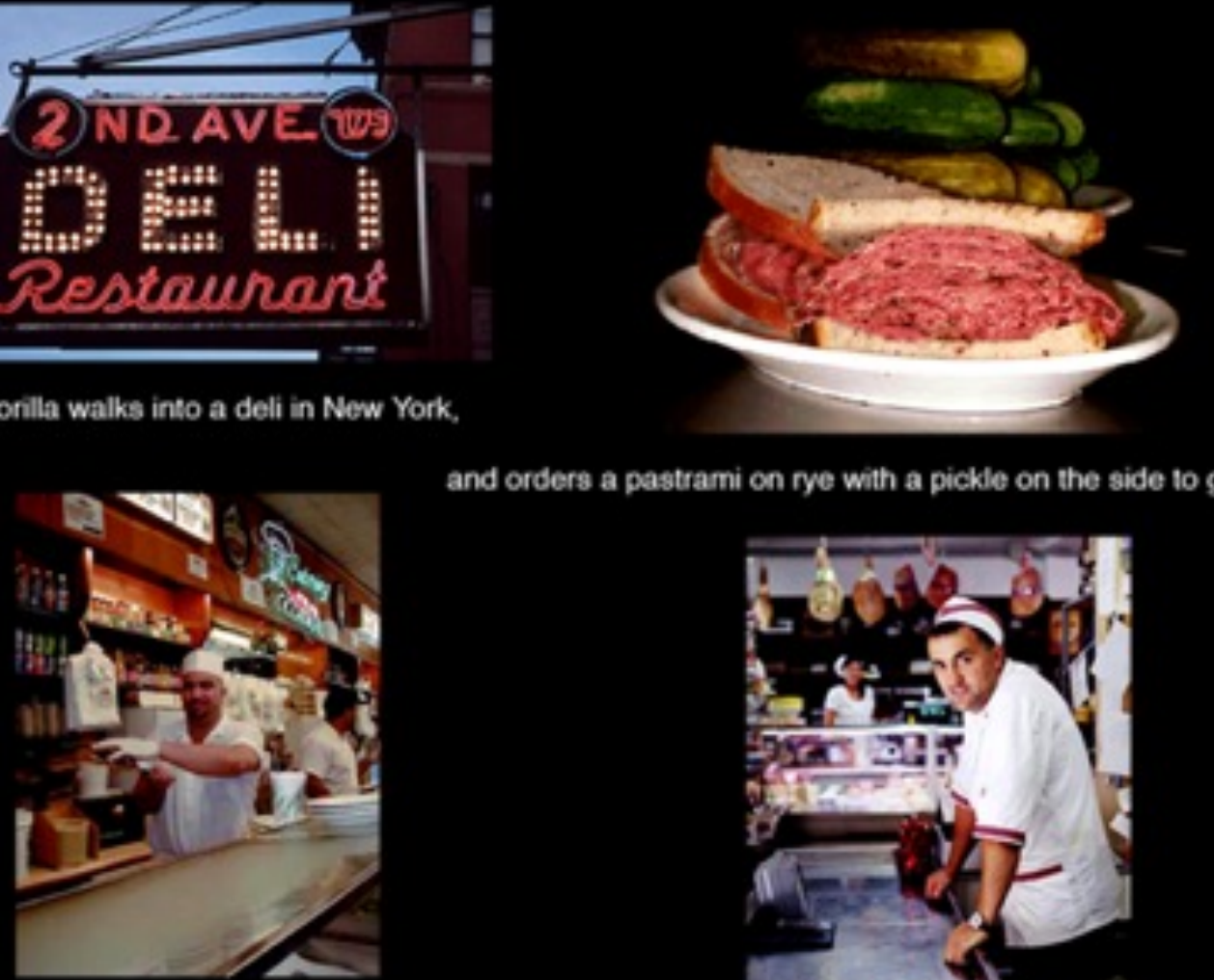

and orders a pastrami on rye with a pickle on the side to go

The guy behind the counter puts the sandwich together and when its ready says. "That'll be twelve dollars."

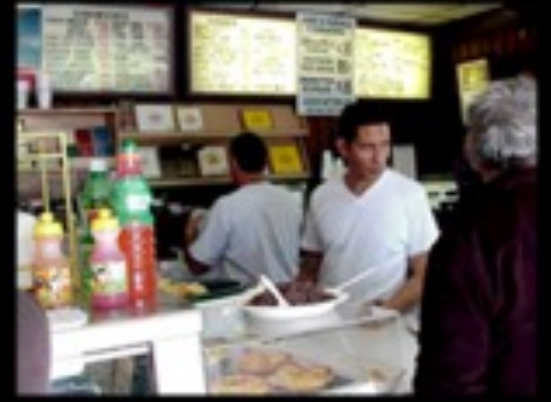

"Uh, I'm sorry sir, but to be honest with you, Ive never seen a gorilla in here betore."

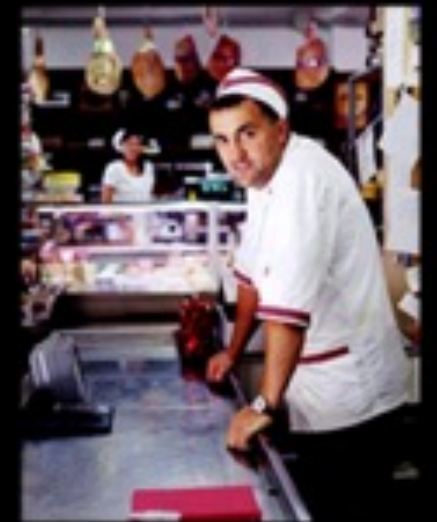

He realizes though that he's been staring. and apologizes.

"You keep charging twelve bucks for a sandwich," says the gorilla, "and you never will again."

Much of the imagery is also objectionable and the juxtapositions are shocking through his use of pornography, "trailer trash," animals smoking, people with extreme disabilities and other absurdist internet obsessions all "mashed up" together with symbols of Jewish identification, political beliefs such as the hammer and sickle and 
Israeli figureheads. There is no hierarchy or differentiation and the flatness itself shocks. Shocks us out of any liberal ideal of a genteel comfort zone in cosmopolitanism or a middle class nomad. All amounts to little in the end as it collapses through the continuing overload. The accumulation of information is so much that the effect is of a build-up of these fragments into a reeling sense of undecideability as the viewer struggles to construct some kind of overall meaning. Through the characters ignorance and parochialism he sees the world and while judgements are made they are annulled by the fluidity and contingency with which he makes those judgements and moves on because he never really understands what is at stake. This is the projection, the delusional fantasy of a putative YouTube subject the obsessive, distrustful but authoritarian conspiracy theorist scouring the net for clues that offer no conclusive answer and no real self-reflection. Maybe somehow the superficiality of this subjectivity offers possibilities for cosmopolitisation through its fluidity and ephemerality of identification.

So importantly Fishbone does not elevate Jewishness. The normalization of Jewishness acknowledges that this is merely one ethnicity amongst many and that it is not special nor more worthy and certainly not fixed. The aim in using the stereotype and the collision of brutal imagery is as an absurdist Dada-esque device. The work of Fishbone situates itself through cosmopolitan ideals, it could be said, through the tactic of deflating all that he represents: the Jewish the educated, middle class subject. He does this as an equalizing manoeuvre of absurdist ignorance. Neither education nor riches release one from prejudice and bigotry in this world-view. No one has the right to laugh at others, nor judge. The critique is present through the juxtaposition and contradictions of the imagery and narrative and the images from one another.

Which brings me to the heart of my claim that my own recuperation of the term 'cosmopolitanism' aims not to make the contentious issue of belonging 'all right' through referencing the nomadic, nor to elevate the home as a site of safety (for it may well be a site of ambivalence, claustrophobia or threat, especially for women ${ }^{27}$ ), but to hold onto the discomfort of not belonging as a radical possibility for 
subjectivity, to normalize the expectation that the subject is always an incomplete project but that incompleteness is a condition of being. Home can never represent total comfort and "belonging" is an impossible if necessary aim.

Novaczek and Fishbone in very different ways situate an incomplete subject of provisionality and discomfort in their work. ${ }^{28}$ Neither of these artists make a home anywhere and but seem to engage in the emotional processes of being unsettled. In this way they posit a contingent subject that is incomplete, analogous to Levy and Sznaider. As art, its incompleteness, however is replete with possibility for the viewer through the cinematic experience, thus taking the it to another level. Novaczek's example is humanist and offers the possibility of redemption through the cosmopolitan and relations with others while Fishbone's vision is post-humanist and seemingly profoundly non-redemptive. However I would argue that the redemption offered is one that is pulled from the equality of the squalid worldview - equality from below. Despite their differences what both artists have in common is a presentation of a subject mired in reiterative provisionality as a positive force that offers a way of being in the world through the celebration of the disparate, the disjunctive and the composite as a new normal. This new normal borne out of a maximalist tendency of contingency and flux that is, I would argue the condition of a Diasporic identity, rather than the nomadic homing, can offer a model for the contemporary cosmopolitan ideal.

${ }^{1}$ October is a journal of Art History, Theory and Criticism. 
${ }^{2}$ Krauss, "Video: The Structure of Narcissism," 50-64.

${ }^{3}$ Garfield, “Towards a Re-articulation,” 99-108.

${ }^{4}$ Adorno's, Aesthetic Theory, and Debord's, The Society of the Spectacle, are two key texts that inform the idea of art as critique that has been the prevalent force for many decades in art. In addition many Modern forms of art such as Dada have established a critical manifesto in the earlier parts of the $20^{\text {th }}$ Century. Finally the idea of an avant-garde in art, which is much discussed and commonplace in relation to modernism particularly assumes a critique on previous art.

5 Buchloh, "The Politics of the Signifier," 7. See also, Garfield, "Towards a ReArticulation of Cultural Identity," 99-108.

${ }^{6}$ Such as From generation to Generation, http://www.jewishmuseum.org.uk/ generation, or Golem, http://www.jmberlin.de/main/EN/01-Exhibitions/02-SpecialExhibitions/2016/golem.phpNormal Kleeblatt, curator at the New York Jewish Museum is a notable exception with a number of groundbreaking and critical exhibitions about contemporary Jewish and Other identities such as Too Jewish? Challenging Traditional Identities (1996).

7 Judy Chicago, a prominent pioneering feminist artist has this on her website explaining her 'Jewish themes'. As a result of the investigation of their Jewish heritage that Chicago and Woodman undertook during the Holocaust Project, Chicago became interested in Jewish themes. Since then, she has created a number of works, including a series of prints based on a recent translation of the Song of Songs along with a number of Judaic ritual objects. These include designs for tallit bags; a unique matzoh cover celebrating the women associated with Passover; and a personal Haggadah for use by the Seder group that she and Woodman have participated in for over twenty years http:/www.judychicago.com/gallery/jewishthemes/jt-artwork/

${ }^{8}$ Bohm-Duchen and Grodzinski, Rubies and Rebels.

${ }^{9}$ Garfield, "Playing With History," 320-339.

${ }^{10}$ Baskind, Jewish Artists and the Bible. I would consider the particularism of the Bible, as in Baskind's book, as part of the dilemma of mining one's particularity for celebratory purposes. The issue of the absence of bible stories in Western art is to do with the importance of Greek mythology as the ideal of Western civilization in opposition to the Hebraic, as outlined by Arnold, Culture and Anarchy.

${ }^{11}$ Levy and Sznaider,’Memories of Europe," 160.

${ }^{12}$ Merskimmon, The Cosmopolitan Imagination, 7-8.,

13 Ibid., 64.

${ }^{14}$ Ahmed, Strange Encounters, 80. 
${ }^{15}$ Cheyette and Marks, Modernity, Culture and 'The Jew.' Cheyette and Marks use the same argument with regard to 'the Jew' as the paradigmatic other in modernity. 'The Jew' as paradigm elides real Jews.

${ }^{16}$ Papastergiadis, Cosmopolitanism and Culture, 9.

${ }^{17}$ Fishbone later worked with a Nollywood director as an actor in a bone fide Nollywood film entitled Elmina (2010) but launched the film at Tate Britain (as well as the director launching the film in the usual Nollywood cinema distribution).

18 Doane, The Emergence of Cinematic Time, 187-194.

${ }^{19}$ Harbord, Rethinking Film Studies, 72.

${ }^{20}$ Mercer, Cosmopolitan Modernisms, 125.

${ }^{21}$ Ibid., 126.

22 Papastergiadis, Cosmopolitanism and Culture, 91.

${ }^{23}$ Ibid., 92.

24 This distinction is complicated as Novaczek did her practice degree at Central St Martins.

${ }^{25}$ Papastergiadis, Cosmopolitanism and Culture, 89.

${ }^{26}$ Beck and Sznaider, "Unpacking Cosmopolitanism," 383. 


\section{Works cited}

Adorno, Theodor W., Aesthetic Theory, Minneapolis: University of Minnesota Press, 1998.

Ahmed, Sarah, Strange Encounters: Embodied Others in Post-Coloniality, London: Routledge, 2000.

Baskind, Samantha, Jewish Artists and the Bible in $20^{\text {th }}$ Century America, Hong Kong: Penn State University Press, 2014

Bohm-Duchen and Grodzinski, Rubies and Rebels: Jewish Female Identity in Contemporary British Art, London: Lund Humphries, 1996

Debord, Guy, The Society of the Spectacle, Black and Red, 2000.

Chambers, Iain, 'Unrealized Democracy and a Posthumanist Art,' Democracy Unrealized: Documenta 11, Platform 1, eds., O. Enwezor, Ostfildern-Ruit: Hatje Cantz, 2002.

Cheyette, Bryan and Marcus, Laura, Modernity, Culture and 'The Jew, 'Polity Press, 1998.

Doane, Mary Ann, The Emergence of Cinematic Time, Cambridge/MA: Harvard University Press, 2002.

Garfield, Rachel, "Towards a Re-articulation of Cultural Identity: Problematizing the Jewish Subject in Art," Third Text, 20, Issue 1, London: Taylor and Francis, 2006.

Garfield, Rachel, "Cosmopolitan Maximalism: Multi-Positionality, Excess and Contingency in the Art of Melanie Jackson and Vivienne Dick," Open Arts Journal, online publicaton, 2013. Available online at: http://

openartsjournal.files.wordpress.com/2013/01/oaj_issue1_lowres_withlinks.pdf,

Garfield, Rachel, “A Particular Incoherence," Between Truth and Fiction: The Films of Vivienne Dick, ed. T. O’Brian, London: Crawford Art Centre/Lux, 2009. 